\title{
UV camera measurements of fumarole field degassing (La Fossa crater, Vulcano Island)
}

\author{
G. Tamburello $^{\text {a,* }}$, E.P. Kantzas ${ }^{\text {b }}$, A.J.S. McGonigle ${ }^{\text {b }}$, A. Aiuppa ${ }^{\text {a,c }}$, G. Giudice $^{\mathrm{c}}$ \\ a Dipartimento di Chimica e Fisica della Terra ed Applicazioni (CFTA), University of Palermo, Italy \\ ${ }^{\mathrm{b}}$ Department of Geography, University of Sheffield, UK \\ ${ }^{\text {c } I s t i t u t o ~ N a z i o n a l e ~ d i ~ G e o f i s i c a ~ e ~ V u l c a n o l o g i a, ~ S e z i o n e ~ d i ~ P a l e r m o ~(I N G V), ~ I t a l y ~}$
}

\section{A R T I C L E I N F O}

\section{Article history:}

Received 25 May 2010

Accepted 13 October 2010

Available online 16 November 2010

\section{Keywords:}

UV camera

fumaroles

Vulcano

volcanic gas

geochemistry

gas emission

\begin{abstract}
A B S T R A C T
The UV camera is becoming an important new tool in the armory of volcano geochemists to derive high time resolution $\mathrm{SO}_{2}$ flux measurements. Furthermore, the high camera spatial resolution is particularly useful for exploring multiple-source $\mathrm{SO}_{2}$ gas emissions, for instance the composite fumarolic systems topping most quiescent volcanoes. Here, we report on the first $\mathrm{SO}_{2}$ flux measurements from individual fumaroles of the fumarolic field of La Fossa crater (Vulcano Island, Aeolian Island), which we performed using a UV camera in two field campaigns: in November 12, 2009 and February 4, 2010. We derived $\sim 0.5 \mathrm{~Hz} \mathrm{SO}$ flux time-series finding fluxes from individual fumaroles, ranging from 2 to $8.7 \mathrm{t} \mathrm{d}^{-1}$, with a total emission from the entire system of $\sim 20 \mathrm{t} \mathrm{d}^{-1}$ and $\sim 13 \mathrm{t} \mathrm{d}^{-1}$, in November 2009 and February 2010 respectively. These data were augmented with molar $\mathrm{H}_{2} \mathrm{~S} / \mathrm{SO}_{2}, \mathrm{CO}_{2} / \mathrm{SO}_{2}$ and $\mathrm{H}_{2} \mathrm{O} / \mathrm{SO}_{2}$ ratios, measured using a portable MultiGAS analyzer, for the individual fumaroles. Using the $\mathrm{SO}_{2}$ flux data in tandem with the molar ratios, we calculated the flux of volcanic species from individual fumaroles, and the crater as a whole: $\mathrm{CO}_{2}\left(684 \mathrm{t} \mathrm{d}^{-1}\right.$ and $\left.293 \mathrm{t} \mathrm{d}^{-1}\right)$, $\mathrm{H}_{2} \mathrm{~S}\left(8 \mathrm{t} \mathrm{d}^{-1}\right.$ and $\left.7.5 \mathrm{t} \mathrm{d}^{-1}\right)$ and $\mathrm{H}_{2} \mathrm{O}\left(580 \mathrm{t} \mathrm{d}^{-1}\right.$ and $\left.225 \mathrm{t} \mathrm{d}^{-1}\right)$.
\end{abstract}

(c) 2010 Elsevier B.V. All rights reserved.

\section{Introduction}

The rate of $\mathrm{SO}_{2}$ release from active volcanoes $\left(\mathrm{SO}_{2}\right.$ flux $)$ is an important parameter for volcano monitoring, as it is acting as a proxy of underground magma ascent rate, thus strongly correlating with eruptive activity (Caltabiano et al., 2004; Burton et al., 2009). Since the 1970s, COSPEC (Stoiber et al., 1983; Caltabiano et al., 1994) and more recently DOAS (McGonigle, 2007) have been the most widely used techniques for ground-based $\mathrm{SO}_{2}$ flux monitoring. These are applied by scanning across the plume cross section, (McGonigle et al., 2003), or traversing beneath the plume with a vehicle, boat, aircraft, or an unmanned aerial vehicle (McGonigle et al., 2008). The derived concentrations are integrated over the profile, then multiplied by plume transport speed to output flux.

In spite of their utility, the scanning and traverse techniques are both subject to several significant limitations: the plume speed is typically assumed to be equal to wind speeds, measured with distal anemometers, contributing to high (potentially $>100 \%$ ) and usually unquantified errors (McGonigle et al., 2005). Moreover, the low time resolution of both techniques hampers detection of flux changes related to transient ( $\leq$ tens of seconds) degassing-driven volcanic phenomena, such as strombolian and vulcanian explosions (McGonigle et al., 2009).

\footnotetext{
* Corresponding author. Dipartimento CFTA, Università di Palermo, Via Archirafi 36, 90123 Palermo, Italy. Tel.: +39 091 23861618; fax: +39 0916168376.

E-mail address: giancarlotamburello@gmail.com (G. Tamburello).
}

In addition, the low spatial resolution of scanning/traverse methods prevents the observer from discriminating between multiple-source $\mathrm{SO}_{2}$ emissions, in particular when they are weak and closely spaced.

Over the last few years, there has been a significant advance in volcanic $\mathrm{SO}_{2}$ flux monitoring with the deployment of UV camera technology. This technique allows capturing of the whole plume, in a single image, thus the possibility to explore spatial variations in $\mathrm{SO}_{2}$ emissions over a timescale of $\sim 1 \mathrm{~s}$ (Mori and Burton, 2006; Bluth et al., 2007; Dalton et al., 2009). The high temporal and spatial resolutions of the UV camera also allow direct calculation of the plume transport velocity, via cross-correlation methods (e.g. McGonigle et al., 2005), hence the significant reduction in the magnitude of this error source. Finally, imaging techniques are particularly valuable in exploring the spatial/temporal heterogeneity of multiple gas source systems. Here we augment the increasing usage of the UV camera to derive bulk plume $\mathrm{SO}_{2}$ flux data, with, to the best of our knowledge, the first application of the camera to investigate the complex degassing behavior of fumarolic systems.

In this study, we follow the protocol for UV camera measurement outlined by Kantzas et al. (2010) to image the sulphur dioxide flux distribution of the fumarolic field of La Fossa crater (Vulcano Island, Aeolian Islands), a small (386 m high) pyroclastic cone in a state of degassing unrest since the late 1970s (Chiodini et al., 1995). In particular, we show that the UV camera can be used to derive volcanic $\mathrm{SO}_{2}$ flux data from individual vents within a fumarolic system, and their relative contribution to the bulk emissions. Our measurements 
were obtained during field surveys performed in November 2009 and February 2010, respectively around the time of an anomalous degassing (heating) event between October and December 2009. In tandem with observations during previous unrests at La Fossa since 1988 (Chiodini et al., 1995), the 2009 degassing event was marked by an increase in fumarole temperature, gas/steam ratio and $\mathrm{CO}_{2}$ concentrations (Istituto Nazionale di Geofisica e Vulcanologia, Sezione di Palermo, unpublished data, 2009). In order to complement our analysis, and derive insights into the 2009 degassing event, we used a portable gas analyzer (MultiGAS) (Aiuppa et al., 2005a; Shinohara, 2005) allowing the real-time in situ measurement of $\mathrm{H}_{2} \mathrm{~S} / \mathrm{SO}_{2}, \mathrm{CO}_{2} /$ $\mathrm{SO}_{2}$ and $\mathrm{H}_{2} \mathrm{O} / \mathrm{SO}_{2}$ molar ratios. This, in tandem with the $\mathrm{SO}_{2}$ fluxes, provided the first assessment of $\mathrm{CO}_{2}, \mathrm{H}_{2} \mathrm{~S}$ (Aiuppa et al., 2005b; Aiuppa et al., 2006b) and $\mathrm{H}_{2} \mathrm{O}$ emission rates from individual vents of the fumarolic field of La Fossa crater, both during and after the unrest.

\section{Hardware and technique}

The UV camera system we used consisted of two Apogee Instruments Alta U260 cameras $(15 \mathrm{~cm} \times 15 \mathrm{~cm} \times 6.25 \mathrm{~cm})$, each with a 16 bit $512 \times 512$ pixel Kodak KAF-0261E thermo-electrically cooled CCD array detector, and powered with a $12 \mathrm{~V}$ battery. The cameras were each affixed to a tripod mounted steel rail and aligned to ensure identical pointing. A Pentax B2528-UV lens of $25 \mathrm{~mm}$ focal length, providing a field of view (FOV) of $\sim 24^{\circ}$ was affixed to each camera.

Each lens had a band pass filter mounted in front of it, centered on $310 \mathrm{~nm}$ and $330 \mathrm{~nm}$, respectively (Asahi Spectra $10 \mathrm{~nm}$ FWHM XBPA310 and XBPA330); the former affected by plume $\mathrm{SO}_{2}$ absorption with the latter wavelengths falling outside the absorption bands. This permitted a qualitative measure of absorbance A per camera pixel:

$A=-\log _{10}\left[\left(\mathrm{IP}_{310} / \mathrm{IB}_{310}\right) /\left(\mathrm{IP}_{330} / \mathrm{IB}_{330}\right)\right]$

where IP and IB are the dark image subtracted plume and background sky images, with the subscripted filters in place. Calibration was achieved using three quartz $\mathrm{SO}_{2}$ cells $(100,212$ and $1060 \mathrm{ppm} \mathrm{m})$, placed immediately in front of the filters, from which column density was plotted against measured $\mathrm{A}$, the slope from which was multiplied by acquired plume image $A$ values to convert them to $\mathrm{ppm} \mathrm{m}$. The calibration was performed immediately prior to each acquisition viewing $\mathrm{SO}_{2}$-free sky at $45^{\circ}$ zenith angle adjacent and away from the fumarolic field, from the measurement location. In both campaigns, the calibration fit line $\mathrm{R}^{2}$ was $>0.999$. The dimensions of a pixel in the slant column density image were calculated from the field of view of the instrument and the measured distance from the camera to the target. Then, taking a suitable row of pixels, we calculated the integrated column amount (ICA) across the plume of interest, and multiplied this by the plume speed (derived by the cross-correlation method) to compute the $\mathrm{SO}_{2}$ flux. For more details about the technique see Kantzas et al. (2010).

The UV camera approach, in common with DOAS, is a passive remote sensing methodology that measures sunlight scattered in the atmosphere towards the sensor. As the light path is not absolutely defined this can introduce errors in the estimation of slant column densities, which have been little considered hitherto. A recent work (Kern et al., 2009) focuses on two aspects of this: the dilution effect and multiple scattering in the plume. The former is exacerbated at large plume-instrument distances and the latter by elevated plume aerosol concentrations. In our study, measurements were made only $\sim 300 \mathrm{~m}$ from the gas and the thin plume was highly transparent, hence we consider errors here to be minimal. As the plume transport speed is defined accurately, using cross correlation, we estimate each flux to suffer errors of only $\pm 15 \%$, therefore.

The applied in house built MultiGAS (Aiuppa et al., 2005a) unit combined an infrared spectrometer for $\mathrm{CO}_{2}$ determination (Gascard II, calibration range $0-4000 \mathrm{ppmv}$; accuracy $\pm 2 \%$; resolution, 0.8 ppmv), electrochemical sensors for $\mathrm{SO}_{2}$ (City Technology, sensor type $3 \mathrm{ST} / \mathrm{F}$, calibration range, $0-200 \mathrm{ppmv}$, accuracy, $\pm 2 \%$, resolution, 0.5 ppmv) and $\mathrm{H}_{2} \mathrm{~S}$ (SensoriC, sensor type 2E, calibration range, 0-50 ppmv, accuracy, $\pm 5 \%$, resolution, $0.7 \mathrm{ppmv}$ ), and temperature (measuring range, from -30 to $70{ }^{\circ} \mathrm{C}$, resolution, $0.01{ }^{\circ} \mathrm{C}$ ) and relative humidity sensors (Galltec, measuring range, 0-100\% Rh, accuracy, $\pm 2 \%$ ). The readings from the latter two were used to calculate water concentration (in ppmv), assuming a constant standard pressure, with the following equation (Jensen et al., 1990):
$\left.\mathrm{H}_{2} \mathrm{O}[\mathrm{ppmv}]=0.61365^{*} \exp \left(\left(17.502^{*} T{ }^{\circ} \mathrm{C}\right]\right) /\left(240.97+T\left[{ }^{\circ} \mathrm{C}\right]\right)\right)^{*} R h\left[\%{ }^{*} 100\right.$

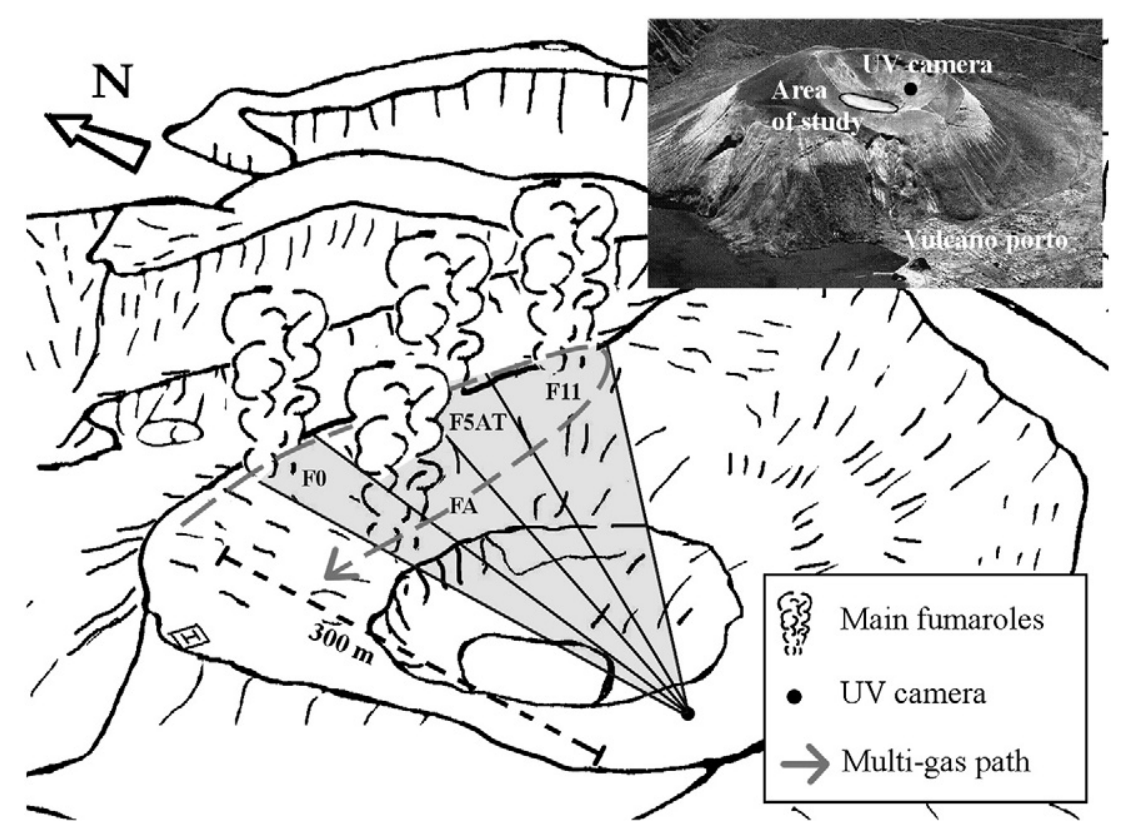

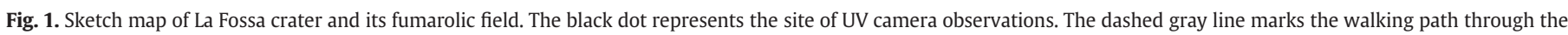
fumarolic field taken during the MultiGAS survey. 
During the measurements, the fumarolic gas was continuously pumped into the sensors at a flow rate of 11 per minute $(\mathrm{lpm})$ through a PTFE tube. A data-logger board captured signals from the sensors every $2 \mathrm{~s}$ and stored the data, while a hand-held GPS provided georeferencing of each datum. The MultiGAS was powered by a $12 \mathrm{~V}, 7 \mathrm{Ah}$ lead battery, and housed inside a waterproof box $(30 \times 20 \times 15 \mathrm{~cm})$.

MultiGAS measurements were performed traversing by foot through the fumarolic field (Fig. 1) with the inlet tube $30-50 \mathrm{~cm}$ from the ground. Using this methodology, we derived the $\mathrm{H}_{2} \mathrm{~S} / \mathrm{SO}_{2}$, $\mathrm{CO}_{2} / \mathrm{SO}_{2}$ and $\mathrm{H}_{2} \mathrm{O} / \mathrm{SO}_{2}$ molar ratios for each from the gradient of the best-fit regression lines in scatter plots for each fumarole. For more details on this technique see Aiuppa et al. (2005a).

\section{Results}

\subsection{UV camera measurements}

The fumarolic field of La Fossa crater is $0.045 \mathrm{~km}^{2}$ wide, which extends $\sim 280 \mathrm{~m}$ along the crater rim and $\sim 180 \mathrm{~m}$ toward the inner. Therefore, the best way to image it entirely via the UV camera, while distinguishing individual fumaroles and using the sky as background, is by observing from the southern inner crater's ridge, 300 m away from the main exhaling area (Figs. 1 and 2).

During the two field campaigns, we sequentially collected images of the four main fumaroles (F0, FA, F5AT, and F11; Figs. 1 and 2) from the measurement position by progressively rotating eastward the UV camera. In both days, imaging of the entire fumarolic system (from F0 to F11 in a W to E cross section) was completed in $~ 20$ min, and each fumarole was observed for periods of 1 to 6 min taking an image every $\sim 2 \mathrm{~s}$.

The wind speed (measured with a hand-held anemometer) ranged from 0 to $0.3 \mathrm{~m} \mathrm{~s}^{-1}$ in November 2010 , and from 3.5 to $7 \mathrm{~m} \mathrm{~s}^{-1}$ in February 2010. The stronger wind in February partially hampered resolving between the different fumaroles (especially F0 and FA, Fig. 3a), which atmospheric dispersions were somewhat overlapping. Of the 206 couples of images of the F0 + FA area taken in February, only 10 were affected by degassing of the FO fumarole, while a mixed F0 + FA plume was captured in the remaining cases. In November 2009, when the wind was instead blowing more gently, the gas was vertically rising (Figs. 2 and 3a), making fumaroles more easily distinguishable.
During both surveys, we processed UV images to calculate $\mathrm{SO}_{2}$ concentration profiles along representative lines perpendicularly oriented to the plume transport direction, and a few meters from the fumarole in question to minimize interference from adjacent sources (Fig. 3a, blue lines); we then calculated $\mathrm{SO}_{2}$ ICAs by integrating pixel concentrations along the profile (corresponding to the shaded area below the $\mathrm{SO}_{2}$ concentration profile). The $\mathrm{SO}_{2}$ concentration profiles were taken horizontally for the November 2009 data, when wind speeds were low $\left(0\right.$ to $\left.0.3 \mathrm{~m} \mathrm{~s}^{-1}\right)$ so the plumes rose vertically; and vertically for the February 2010 data, when the wind blew from the south-east and rather more strongly ( 3.5 to $6 \mathrm{~m} \mathrm{~s}^{-1}$ ) so the gases propagated quasi-horizontally. An example of F0 fumarole's ICA record for the November survey is given in Fig. 4, showing typical smooth fluctuations in gas emissivity over a timescale of 10-20 s. During the February survey, more irregular temporal ICA trends were observed: as the wind speed increased, the gas plume eventually grounded or went out of the field of view, precluding any retrieval (no ICA data were calculated in such high wind conditions). Plume transport speed was calculated by a cross-correlation method (Fig. 3b); this minimizes the error due to the plume speed uncertainty, especially if we derive the shift using multiple sections (the yellow line in Fig. 3a) in an image. The so-calculated plume speed ranged from $\sim 2 \mathrm{~m} \mathrm{~s}^{-1}$ (November) to $\sim 6 \mathrm{~m} \mathrm{~s}^{-1}$ (February). Finally, the $\mathrm{SO}_{2}$ flux was calculated combining ICA and plume speed, as shown in Fig. 4: this allows deriving, for each main vent of the fumarolic system and with a high time resolution, a record of subtle $\mathrm{SO}_{2}$ flux variations.

$\mathrm{SO}_{2}$ flux results are summarized in the box plot in Fig. 5. This clearly highlights that, in both surveys, the FA fumarole was the main degassing area, accounting for $\sim 50 \%$ of the bulk $\mathrm{SO}_{2}$ degassing. The total $\mathrm{SO}_{2}$ flux from the volcano, calculated by summing contributions from the 4 exhaling areas varied from $\sim 21 \mathrm{t} \mathrm{d}^{-1}$ in November 2009 (dotted box) to $\sim 12 \mathrm{t} \mathrm{d}^{-1}$ in February 2010 (filled box), a factor $\sim 2$ larger in the former case during the degassing/heating event than in the latter, when the fumaroles were cooling down (Istituto Nazionale di Geofisica e Vulcanologia, Sezione di Palermo, unpublished data, 2009). These results are qualitatively similar to those presented by Aiuppa et al. (2006a), who, while using a very different $\mathrm{SO}_{2}$ flux retrieval technique (walking traverses with a zenith-pointed UV spectrometer), derived $\mathrm{SO}_{2}$ fluxes of $33 \mathrm{t} \mathrm{d}^{-1}$ and $35 \mathrm{t} \mathrm{d}^{-1}$ during the two unrests in the 2004-2006 period, and factor 2-3 lower fluxes (from 2 to $18 \mathrm{t} \mathrm{d}^{-1}$ ) in the periods in between.
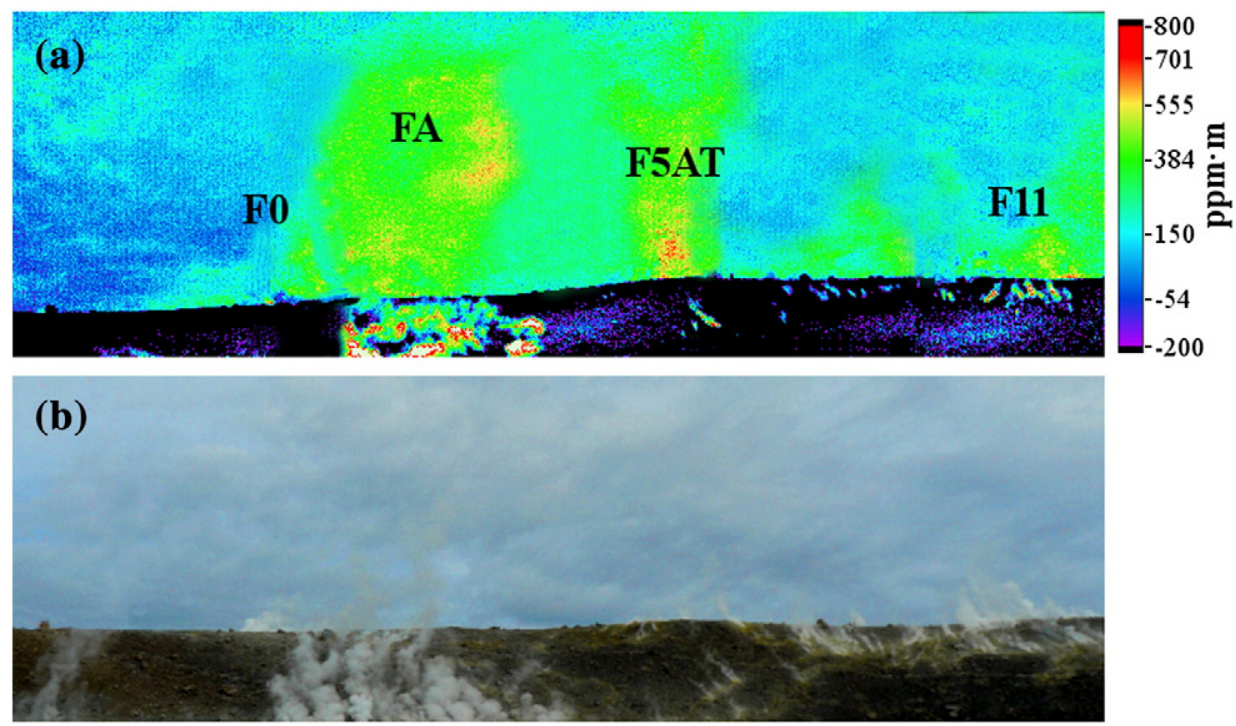

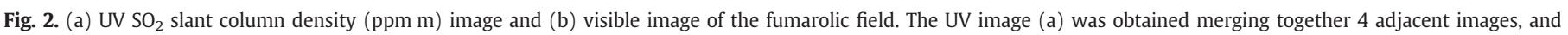
correcting the lens distortion effect on the border of each image which would prevent accurate overlap. 
(a)
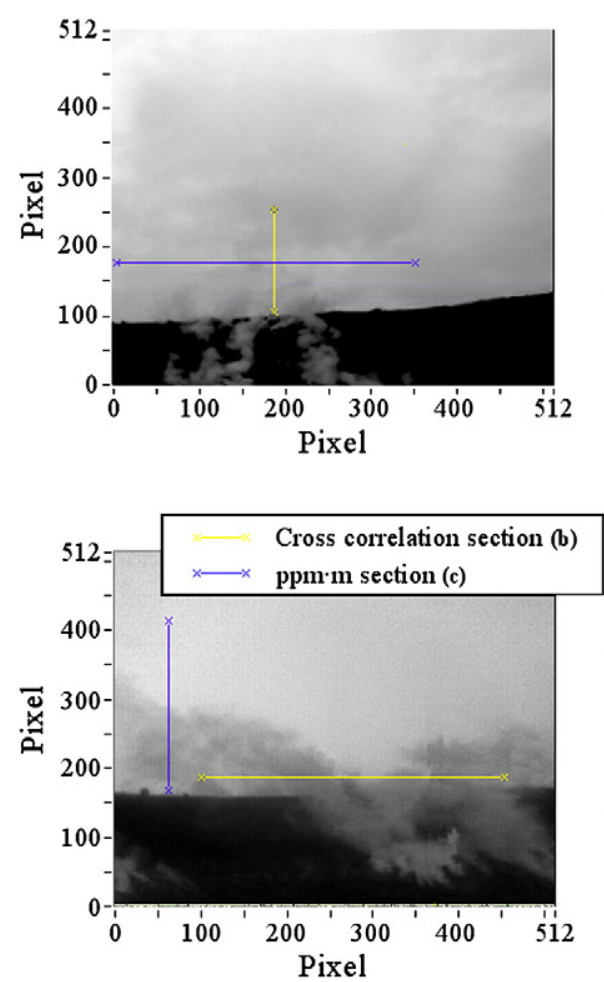

(b)
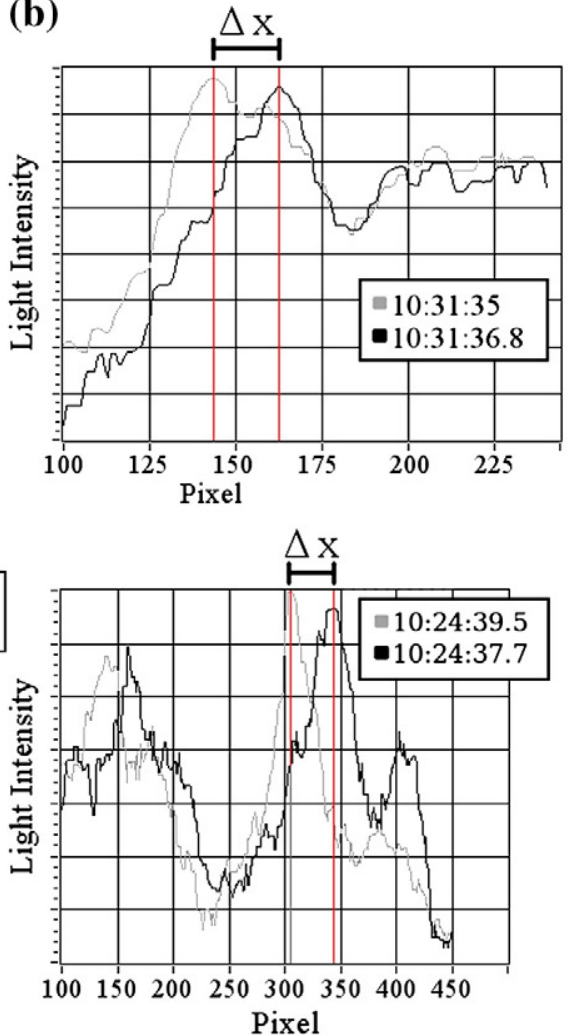

(c)
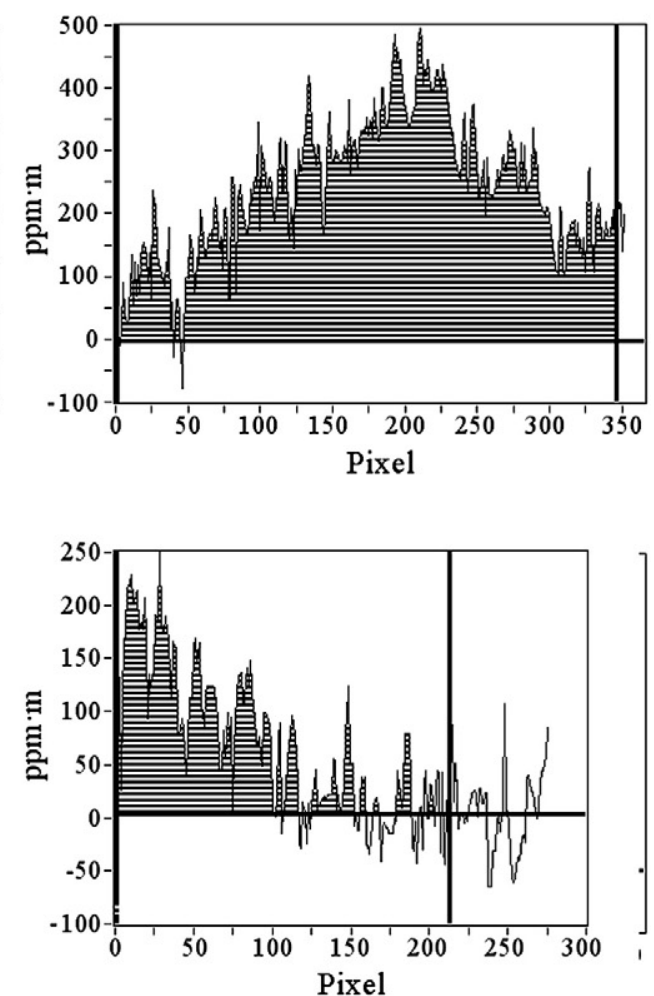

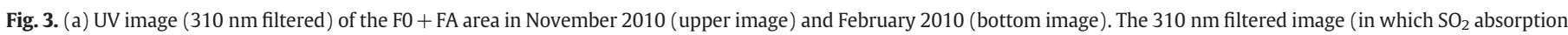

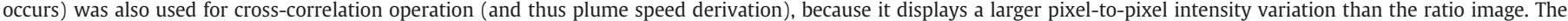

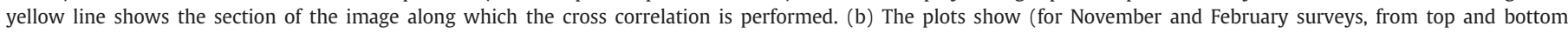

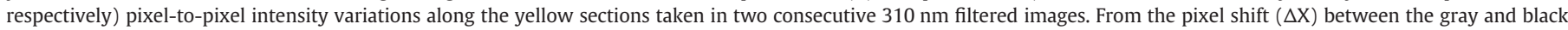

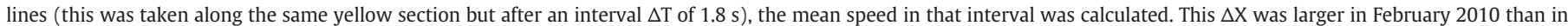

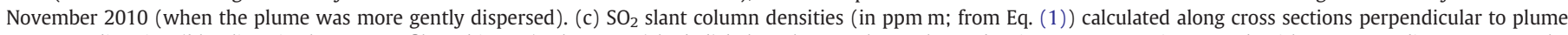

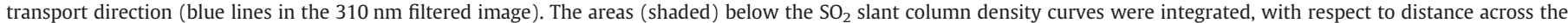
plume, to derive integrated column amount (ICA). The thick black lines mark the integration boundaries.

\subsection{MultiGAS measurements}

During each campaign, we also made MultiGAS traverses to derive the spatial distribution of plume $\mathrm{H}_{2} \mathrm{~S} / \mathrm{SO}_{2}, \mathrm{CO}_{2} / \mathrm{SO}_{2}$ and $\mathrm{H}_{2} \mathrm{O} / \mathrm{SO}_{2}$ molar ratios over the fumarolic field (Fig. 6). In agreement with Aiuppa et al. (2005a), we observed contrasting compositions for the four representative fumarolic areas (F0, F5AT, F11, and FA). Fig. 6 shows our results, illustrating that the $\mathrm{H}_{2} \mathrm{O} / \mathrm{SO}_{2}$ and $\mathrm{H}_{2} \mathrm{~S} / \mathrm{SO}_{2}$ molar ratios varied mostly widely, ranging from $\sim 30$ to $\sim 220$, and from $\sim 0.6$ to $\sim 3.4$,

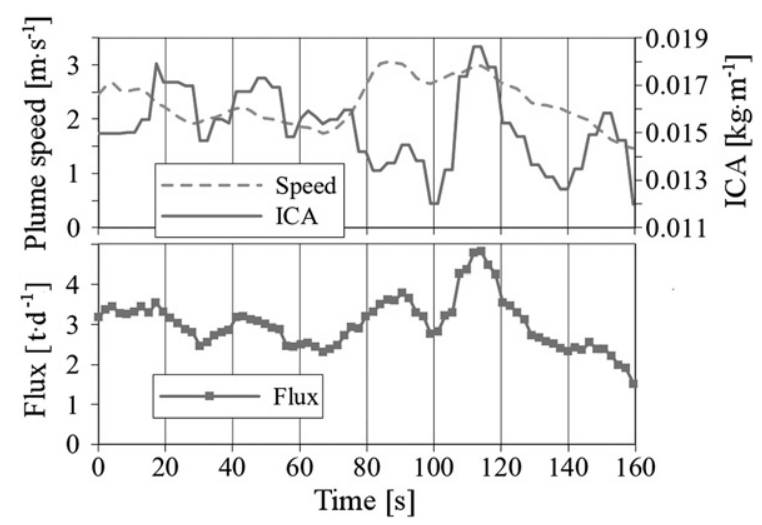

Fig. 4. An example ICA record for the November survey (F0 fumarole). The $\mathrm{SO}_{2}$ flux (in $\left.\mathrm{t} \mathrm{d}^{-1}\right)$ was obtained by multiplying the plume speed $\left(\mathrm{m} \mathrm{s}^{-1}\right)$ by the integrated column amount $\left(\mathrm{kg} \mathrm{m}^{-1}\right)$. respectively across the field. The FA fumarole, which is the hottest vent and typically displays the most magmatic chemical signature (Nuccio and Paonita, 2001), was characterized by lower $\mathrm{H}_{2} \mathrm{~S} / \mathrm{SO}_{2}$, and higher $\mathrm{CO}_{2} / \mathrm{SO}_{2}$ and $\mathrm{H}_{2} \mathrm{O} / \mathrm{SO}_{2}$ molar ratios, than the rim fumaroles (e.g., F0), where hydrothermal gas contribution becomes more important, so $\mathrm{H}_{2} \mathrm{~S}$ prevails over $\mathrm{SO}_{2}$ (as is typical of hydrothermallybuffered gases). As previously noted (Aiuppa et al., 2005a), the F11 fumarole has $\mathrm{H}_{2} \mathrm{~S} / \mathrm{SO}_{2}$ and $\mathrm{CO}_{2} / \mathrm{SO}_{2}$ ratios intermediate between $\mathrm{FO}$ and FA.

The MultiGAS sensed gas $/ \mathrm{SO}_{2}$ ratios, when scaled to the $\mathrm{SO}_{2}$ flux estimates described earlier, allow derivation of $\mathrm{CO}_{2}, \mathrm{H}_{2} \mathrm{O}$ and $\mathrm{H}_{2} \mathrm{~S}$ for individual fumaroles, according to:

Gas flux (e.g., $\mathrm{CO}_{2}$ flux $)=\mathrm{Gas}\left(\right.$ e.g., $\left.\mathrm{CO}_{2}\right) / \mathrm{SO}_{2} \cdot \mathrm{SO}_{2}$ flux.

Results are summarized in Fig. 5.

\section{Discussion and conclusions}

Since 1988, $\mathrm{SO}_{2}$ flux measurements have been performed on La Fossa crater by traversing beneath the plume by boat, car, or by foot (Aiuppa et al., 2006a); or scanning the gas plume from a fixed position (McGonigle et al., 2005). This has led to bulk $\mathrm{SO}_{2}$ fluxes, with time resolutions, at best, of minutes to hours. Neither the traverse nor the scanning techniques were able, however, to resolve short-term fluctuation of the $\mathrm{SO}_{2}$ degassing rate (over timescales less than minutes), or, more importantly in this case, to derive the relative contribution of the different fumaroles to the overall $\mathrm{SO}_{2}$ flux. The 

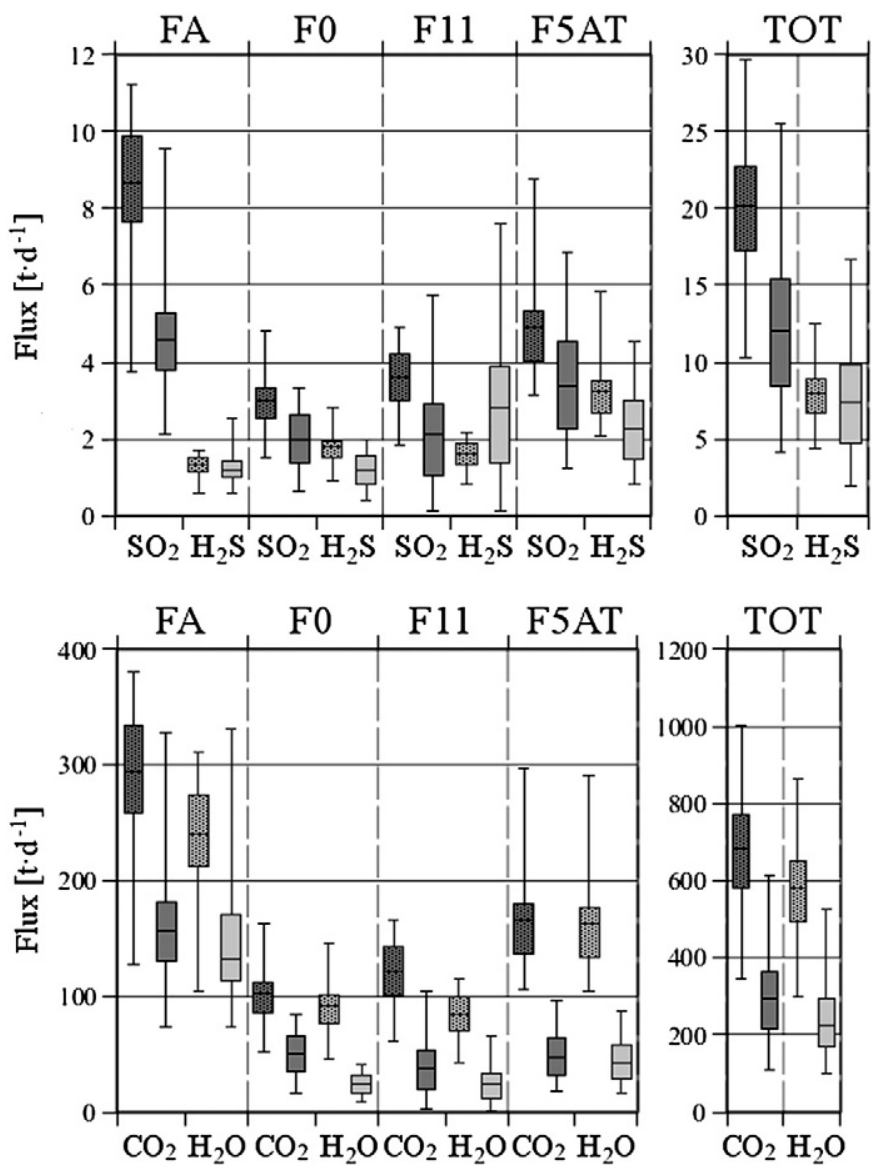

Fig. 5. Box plot showing $\mathrm{SO}_{2}$ and $\mathrm{H}_{2} \mathrm{~S}$ (top), and $\mathrm{CO}_{2}$ and $\mathrm{H}_{2} \mathrm{O}$ (bottom) fluxes from individual fumaroles and for the entire field in November 2009 (dotted box) and February 2010 (filled box). An overall decrease in gas fluxes between the two surveys is evident. The error bars have been calculated based on uncertainties on molar ratio derivation and $\mathrm{SO}_{2}$ flux variability during the measurements. latter limitation is particularly significant for the derivation of volcanic fluxes for other gas species, e.g., $\mathrm{CO}_{2}$, or $\mathrm{H}_{2} \mathrm{O}$ : the traditional approach of scaling the bulk volcano's $\mathrm{SO}_{2}$ flux by the composition of a single emission vent, assumed to be representative of the whole field, is clearly inaccurate for relatively large and chemically heterogeneous fumarolic fields like La Fossa. In such circumstances, composition and flux data for each of the main degassing areas are necessary.

In this work we took advantage of the high spatial $(0.3 \mathrm{~m}$ per pixel) and time resolution $(\sim 0.5 \mathrm{~Hz})$ of the UV camera (Kantzas et al., 2010) to propose a new approach for exploring multiple-source $\mathrm{SO}_{2}$ gas emissions from fumarolic fields. The camera-derived individual fumarole $\mathrm{SO}_{2}$ fluxes (Figs. 4 and 5), when coupled with MultiGAS (Aiuppa et al., 2005a) derived gas $/ \mathrm{SO}_{2}$ molar ratios for a number of fumaroles (Fig. 6), allowed us to accurately assess $\mathrm{CO}_{2}, \mathrm{H}_{2} \mathrm{O}$, and $\mathrm{H}_{2} \mathrm{~S}$ fluxes (Fig. 5), and thus to refine previous gas inventories from the volcano (Aiuppa et al., 2005a; McGonigle et al., 2008).

Fig. 5 shows that the major components $\mathrm{H}_{2} \mathrm{O}$ and $\mathrm{CO}_{2}$ are mainly contributed by the FA fumarole, and by the F5AT fumarole to a lesser extent. In contrast, the FA area only marginally contributes to the volcano's $\mathrm{H}_{2} \mathrm{~S}$ budget, which is instead dominated by the rim fumaroles (F11 and F5AT in particular).

Our results also clearly show that there was a factor $\sim 2$ increase in total $\mathrm{CO}_{2}$ degassing from the fumarolic system during La Fossa crater degassing/heating unrest (the derived $\mathrm{CO}_{2}$ fluxes were $680 \mathrm{t} \mathrm{d}^{-1}$ in November 2009, and $290 \mathrm{t} \mathrm{d}^{-1}$ in February 2010; Fig. 5). Our mean $\mathrm{CO}_{2}$ flux of $\sim 490 \mathrm{t} \mathrm{d}^{-1}$ (average of the two surveys) is between 2 and 6 times larger than that of the $\mathrm{CO}_{2}$ flux diffusely degassed from soils in the Vulcano Porto area (Chiodini et al., 1996), highlighting that the central conduit system feeding the fumaroles is the main gas transfer path. We also evaluate a mean $\mathrm{H}_{2} \mathrm{O}$ flux of $\sim 400 \mathrm{t} \mathrm{d}^{-1}$, close to earlier estimates by Italiano et al. (1998) and Chiodini et al. (2005). We additionally confirm that the $\mathrm{H}_{2} \mathrm{O}$ flux is also larger during La Fossa heating events than in "cold" periods $\left(580 \mathrm{t} \mathrm{d}^{-1}\right.$ in November 2009 and $225 \mathrm{t} \mathrm{d}^{-1}$ in February 2010); supporting the idea that recurrent heating unrests on La Fossa fumarolic field reflect an enhanced rate of hot (deep rising) gas transport to the surface. In contrast, the total $\mathrm{H}_{2} \mathrm{~S}$ flux was apparently not affected by the heating event $\left(8 \mathrm{t} \mathrm{d}^{-1}\right.$ in November 2009 and $7.5 \mathrm{t} \mathrm{d}^{-1}$ in February 2010). Our mean $\mathrm{H}_{2} \mathrm{~S}$ flux of $\sim 7.7 \mathrm{t} \mathrm{d}^{-1}$ is consistent, or slightly higher, than previous estimates:

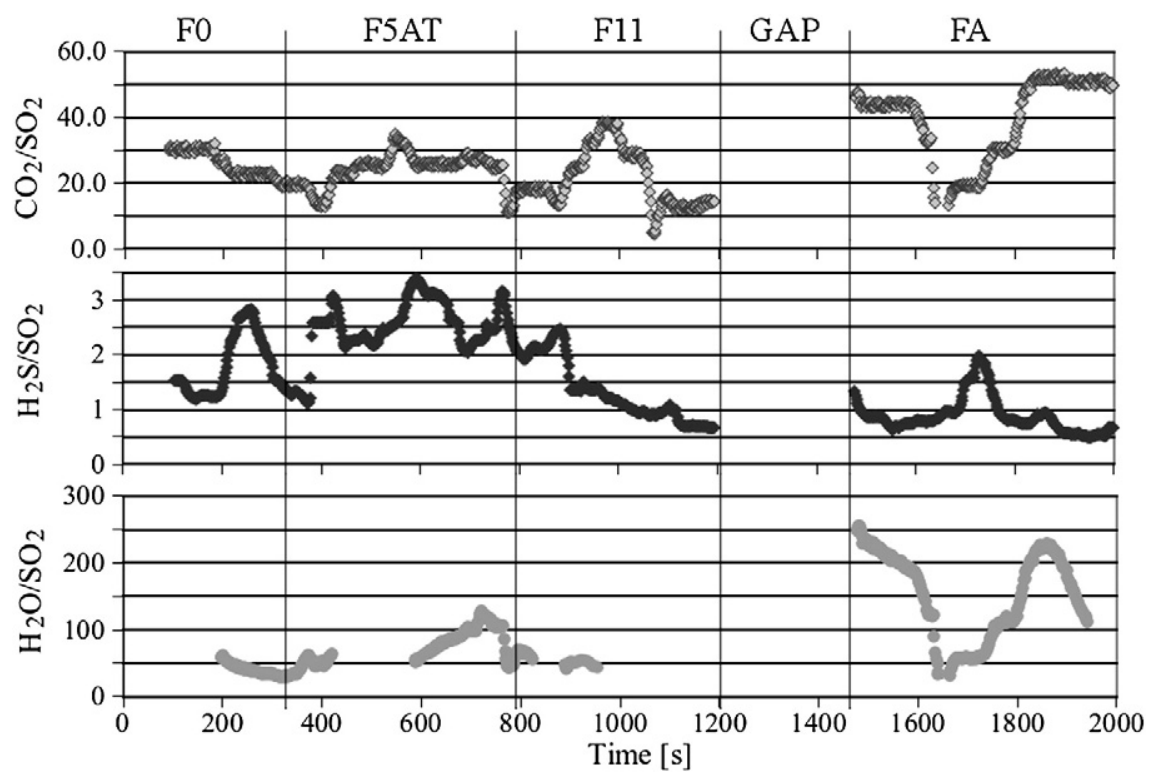

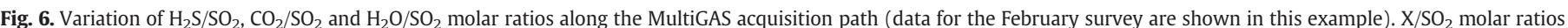

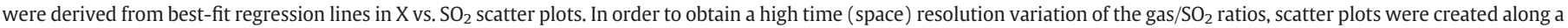

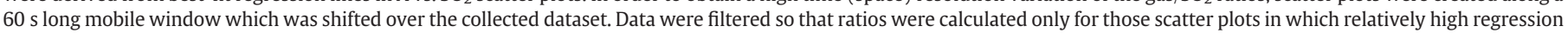
coefficients $\left(R^{2}\right.$ values $\left.>0.6\right)$ were obtained. The central data gap is due to the absence of fumaroles between the F11 and the FA. 
from $\sim 6 \mathrm{t} \mathrm{d}^{-1}$ in 2003 (Aiuppa et al., 2005b) to $\sim 4 \mathrm{t} \mathrm{d}^{-1}$ in 2004 (Aiuppa et al., 2005a). Since $\mathrm{H}_{2} \mathrm{~S}$ is a hydrothermally derived gas component, our observations suggest that a deep magmatic $\left(\mathrm{CO}_{2}\right.$-rich and $\mathrm{H}_{2} \mathrm{~S}$-poor) reservoir was likely sourcing the anomalously high gas emissions in November 2009, and indeed during other degassing/ heating events.

We conclude that systematic and integrated UV camera/MultiGAS monitoring of gas fluxes could improve our understanding of degassing processes, and contribute to volcanic hazard assessment. Indeed, our measuring technique was sensitive enough to detect the increase in gas fluxes during the La Fossa crater heating events.

\section{Acknowledgements}

The authors wish to thank Sergio Gurrieri of INGV-Palermo who has supported this work and Marcello Bitetto for his help during the field work. Kantzas E. P. acknowledges support of an AXA Post Doctoral Fellowship.

\section{References}

Aiuppa, A., Federico, C., Giudice, G., Gurrieri, S., 2005a. Chemical mapping of a fumarolic field: La Fossa Crater, Vulcano Island (Aeolian Islands, Italy). Geophysical Research Letters 32, L13309. doi:10.1029/2005GL023207.

Aiuppa, A., Inguaggiato, S., McGonigle, A.J.S., O'Dwyer, M., Oppenheimer, C., Padgett, M., Rouwet, D., Valenza, M., 2005b. $\mathrm{H}_{2} \mathrm{~S}$ fluxes from Mt. Etna, Stromboli, and Vulcano (Italy) and implications for the sulfur budget at volcanoes. Geochimica et Cosmochimica Acta 69, 1861-1871. doi:10.1016/j.gca.2004.09.018.

Aiuppa, A., Federico, C., Giudice, G., Gurrieri, S., Valenza, M., 2006a. Hydrothermal buffering of the $\mathrm{SO}_{2} / \mathrm{H}_{2} \mathrm{~S}$ ratio in volcanic gases: evidence from La Fossa Crater fumarolic field, Vulcano Island. Geophysical Research Letters 33, L21315. doi:10.1029/2006GL027730.

Aiuppa, A., Federico, C., Giudice, G., Gurrieri, S., Liuzzo, M., Shinohara, H., Favara, R., Valenza, M., 2006b. Rates of carbon dioxide plume degassing from Mount Etna volcano. Journal of Geophysical Research 111, B09207. doi:10.1029/2006JB004307.

Bluth, G.J.S., Shannon, J.M., Watson, I.M., Prata, A.J., Realmuto, V.J., 2007. Development of an ultra-violet digital camera for volcanic $\mathrm{SO}_{2}$ imaging. Journal of Volcanology and Geothermal Research 161, 47-56.

Burton, M.R., Caltabiano, T., Murè, F., Salerno, G., Randazzo, D., 2009. $\mathrm{SO}_{2}$ flux from Stromboli during the 2007 eruption: results from the FLAME network and traverse measurements. Journal of Volcanology and Geothermal Research 182, 214-220.

Caltabiano, T., Romano, R., Budetta, G., 1994. $\mathrm{SO}_{2}$ flux measurements at Mount Etna (Sicily). Journal of Geophysical Research 99, 12809-12819.

Caltabiano, T., Burton, M., Giammanco, S., Allard, P., Bruno, N., Murè, F., Romano, R., 2004. Volcanic gas emissions from the summit craters and flanks of Mt. Etna, 19872000. In: Bonaccorso, A., Calvari, S., Coltelli, M., Del Negro, C., Falsaperla, S. (Eds.), Mt Etna: Volcano Laboratory: American Geophysical Union, Geophysical Monography, 143, pp. 111-128.
Chiodini, G., Cioni, R., Marini, L., Panichi, C., 1995. Origin of the fumarolic fluids of Vulcano Island, Italy, and implications for the volcanic surveillance. Bulletin of Volcanology 57, 99-110.

Chiodini, G., Frondini, F., Raco, B., 1996. Diffuse emission of $\mathrm{CO}_{2}$ from the Fossa crater, Vulcano Island (Italy). Bulletin of Volcanology 58, 41-50.

Chiodini, G., Granieri, D., Avino, R., Caliro, S., Costa, A., Werner, C., 2005. Carbon dioxide diffuse degassing and estimation of heat release from volcanic and hydrothermal systems. Journal of Geophysical Research 110, B08204. doi:10.1029/2004JB003542.

Dalton, M.P., Watson, I.M., Nadeau, P.A., Werner, C., Morrow, W., Shannon, J.M., 2009 Assessment of the UV camera sulfur dioxide retrieval for point source plumes. Journal of Volcanology and Geothermal Research 188, 358-366. doi: 10/016/j. jvolgeores.2009.09.013.

Italiano, F., Pecoraino, G., Nuccio, P.M., 1998. Steam output from fumaroles of an active volcano: tectonic and magmatic-hydrothermal controls on the degassing system at Vulcano (Aeolian arc). Journal of Geophysical Research 103, 29829-29842. doi:10.1029/98JB02237.

Jensen, M.E., Burman, R.D., Allen, R.G., 1990. Evapotranspiration and irrigation water requirements. ASCE Manuals and Reports on Engineering Practice No. 70. Am. Soc. Civil Engr, New York, NY. (332 pp.).

Kantzas, E.P., McGonigle, A.J.S., Tamburello, G., Aiuppa, A., Bryant, R.G., 2010. Protocols for UV camera volcanic $\mathrm{SO}_{2}$ measurements. Journal of Volcanology and Geothermal Research 194, 55-60. doi:10.1016/j.jvolgeores.2010.05.003.

Kern, C., Deutschmann, T., Vogel, L., Wöhrbach, M., Wagner, T., Platt, U., 2009. Radiative transfer corrections for accurate spectroscopic measurements of volcanic gas emissions. Bulletin of Volcanology 72, 233-247. doi:10.1007/s00445-009-0313-7.

McGonigle, A.J.S., Oppenheimer, C., Galle, B., Edmonds, M., Caltabiano, T., Salerno, G., Burton, M., 2003. Volcanic sulphur dioxide flux measurements at Etna, Vulcano and Stromboli obtained using an automated scanning static ultraviolet spectrometer Journal of Geophysical Research 108 (B9), 2455. doi:10.1029/2002JB002261.

McGonigle, A.J.S., Inguaggiato, S., Aiuppa, A., Hayes, A.R., Oppenheimer, C., 2005. Accurate measurement of volcanic $\mathrm{SO}_{2}$ flux: determination of plume transport speed and integrated $\mathrm{SO}_{2}$ concentration with a single device. Geochemistry, Geophysics, Geosystems 6, Q02003. doi:10.1029/2004GC000845.

McGonigle, A.J.S., 2007. Measurement of volcanic $\mathrm{SO}_{2}$ fluxes with differential optical absorption spectroscopy. Journal of Volcanology and Geothermal Research 162 111-122. doi:10.1016/j.jvolgeores.2007.02.001.

McGonigle, A.J.S., Aiuppa, A., Giudice, G., Tamburello, G., Hodson, A.J., Gurrieri, S., 2008 Unmanned aerial vehicle measurements of volcanic carbon dioxide fluxes. Geophysical Research Letters 35, L06303. doi:10.1029/2007GL032508.

McGonigle, A.J.S., Aiuppa, A., Ripepe, M., Kantzas, E.P., Tamburello, G., 2009 Spectroscopic capture of $1 \mathrm{~Hz}$ volcanic $\mathrm{SO}_{2}$ fluxes and integration with volcano geophysical data. Geophysical Research Letters 36, L21309. doi:10.1029/ 2009GL040494.

Mori, T., Burton, M.R., 2006. The $\mathrm{SO}_{2}$ camera: a simple, fast and cheap method for groundbased imaging of $\mathrm{SO}_{2}$ in volcanic plumes. Geophysical Research Letters 161 (33) 47-56.

Nuccio, P.M., Paonita, A., 2001. Magmatic degassing of multicomponent vapors and assessment of magma depth: application to Vulcano Island (Italy). Earth and Planetary Science Letters 193, 467-481.

Shinohara, H., 2005. A new technique to estimate volcanic gas composition: plume measurements with a portable multi-sensor system. Journal of Volcanology and Geothermal Research 143, 319-333.

Stoiber, R.E., Malinconico, L.L., Williams, S.N., 1983. Use of the correlation spectrometer at volcanoes. In: Tazieff, H., Sabroux, J.C. (Eds.), Forecasting Volcanic Events. Elsevier, Amsterdam, pp. 425-444. 